\title{
Research promotion in Vietnamese higher education: how to enhance research activities at a young and dynamic university
}

\author{
Anh Le Thi Phuong ${ }^{1}$, Huyen K. Pham ${ }^{1}$ \\ ${ }^{1}$ FPT UNIVERSITY, HA NOI, VIETNAM
}

\begin{abstract}
The purpose of this paper is to analyze the development of research on higher education in Vietnam. A case study research approach was utilized to examine the quality growth of a private Vietnamese university in terms of research for the past six years. The number of international publications and researchers are analyzed in order to evaluate the effectiveness of the university's research-enhancing activities. The results will contribute to improving the quality of training and further contribute to the vision of bringing Vietnamese universities upon the world's educational ranking. Although this research is limited from the perspective of Vietnam, it provides a good illustration of sustainable development of quality in higher educational systems, especially for young universities in developing countries.
\end{abstract}

\section{Introduction}

The world's educational activities have long been paying much attention to teaching and training. However, with the current digital age's developments, information could be accessed in minutes, even seconds. According to Vuong (2019[1]), asking students to rigidly rely on textbooks will limit their ability to access knowledge. Research has thus created a reasonable ecosystem to support teaching and training. Through research, the faculties are constantly updated with new results and methods that are produced every minute of a day. 
This new knowledge will help them adapt the curricula and training programs so that students have continuous access to important sources of knowledge. In addition, postgraduate education or mentoring doctoral students also requires the faculty to have a certain understanding of research activities.

In this sense, several studies have considered research as a backbone of university ranking and its outcomes. However, if university academics are not adept in conducting research, this undertaking will not live up to its name and nature. Hence, it is important to look into two things when dealing with research in higher education:

1. the capability of the faculty members and students to conduct research; and

2. the quality of research being conducted by faculty members and students.

The second point could be expressed through a product called international publication. [2]The publication of research results in international refereed journals is used as an indicator of research strength and quality in institutions and countries.

[3]In particular, Vietnamese education has long been dominated by a model that separated higher education and research. In this model, universities oversaw higher education and training while research institutes focused on research. At the present time, this model has been adjusted, and the two functions are now assigned to both universities and research institutes. Nevertheless, where would Vietnam stand on the world education map for its research given such a late starting point? Are Vietnamese universities, especially young ones who lack the backing up from the Ministry of Training and Education and government bodies, finding ways to make sure the young generations of students they serve will not miss out on opportunities to develop their own research skills and results? These are the matters that this paper is set to find out.

In the next sections, the big picture of research in higher education worldwide and in Vietnam is described as an overview for the paper's main objective. A case study research approach is used to show how a young and private Vietnamese university strived to develop its research capacity and results by implementing several notable research-enhancing policies. Then, data on the growth is analyzed and discussed based on such implementations. Finally, we take it a step further to look at the future of research activities of this university in particular and the whole Vietnamese higher education in general, suggesting changes that need to be made in order to ensure sustainable development in Vietnamese higher education in terms of research activities.

\section{Literature Review}

\subsection{The role of research in higher education}

Higher education institutions are expected to create and disseminate knowledge with the contributions of students and professionals through instruction, extension, outreach, production, or research. While teaching has long been the primary way to pass down knowledge, research and international publications are becoming more and more critical to universities (Vuong, 2019[1]). Scientific research, with the most specific goal of creating a new amount of scientific information of a quality that can surpass critics for international publication, move towards knowledge, raise questions, and even solve problems.

Research creates original knowledge, contributing to each individual's understanding of life and society. The creation of original knowledge also improves the professional capacity of each faculty, adding to the development and training of future generations. Research also contributes directly to building brand and trust in the education sector. 
It has become quite common for a university to have two important functions: training and research (Tran, 2013[4]). These two functions share an organic relationship, in which the active participation of the university faculty in scientific research activities is one of the important measures required and necessary to improve the quality of training. When a university's faculty participates in research, they will gain benefits including but not limited to deepening knowledge, updating knowledge, developing critical thinking and effective analytical skills, and creating an environment that increases the research capacity of the university itself. The latest could be linked to improving essential social relationships on exchanging knowledge among peers and universities.

[5]Currently, the task of improving research capacity for lecturers is still not an attractive investment option for universities, especially in developing countries where universities often put more importance on the teaching function of faculty members (Pham \& Hayden, 2019 [6]; Salmi \& Pham, 2019[7]; Tran \& Nghia, 2020[8]). Around the world, organizations, and scientific circles in Asia, Africa, and even Europe still face obstacles in their scientific publication process. While researchers in Western countries face problems in the thorough understanding and preparation of scientific publishing, ineffective criticism and the need for additional scientific research (Lyytinen et al., 2007[9]), the difficulties for researchers in Asia and Africa could be boiled down to technical issues such as language barriers, budget, and access to scientific journals; but also a lack of research skills in certain cases (Pho \& Tran, 2016[10]). The next section looks at the challenges for research development in a particular ASEAN country - Vietnam.

\subsection{Research in Vietnamese higher education}

\subsubsection{Overview and history}

[11]In the past, research in Vietnam was performed largely outside universities in an academy of sciences, as in many systems influenced by the Soviet model. In the mid-1990s, research was added to the core functions of universities, but attention to research remained low until the research support framework and research performance were incorporated into institutional accreditation standards (Pham, 2012[12]). Over the past decade, the Vietnamese government has made efforts to increase the research capacity of Vietnam's higher education system (Tran et al., 2020[3]). Vietnamese academic staff have been encouraged or, in certain circumstances, required, to submit research to international publications (i.e., publications indexed by citation databases such as ISI Web of Science and Scopus).

A study by the OECD[11] has stated that between 2011 and 2017, the number of workers contributing to intramural research and development (R\&D) activities in Viet Nam slowly increased. The state is a major employer of researchers in Viet Nam - in 2017, it employed every second researcher, a share up to five times higher than other countries in the region. Nevertheless, by international standards, Vietnam's research performance is referred to as 'modest'. Vietnamese Higher Education's Bibliometric indicators, using the Scopus database, show how the gap in publishing performance between Vietnam and two of its neighboring ASEAN member states, Thailand and Malaysia, has been widening since 2001 (Scimago, 2017[13]). Vietnam produces a relatively small number of peer-refereed international publications per one million of the population (Pham Duy Hien 2010[14]). Tables 1 and 2 illustrate Vietnam's stand on the ASEAN educational playground in terms of a number of publications. 
Table 1. Number of publications of six majors ASEAN countries (from ISI Web of Science and Scimago/Scopus and summarized by Tran et al, 2020)

\begin{tabular}{|c|c|c|c|c|c|c|}
\hline \multicolumn{4}{|c|}{ ISI Web of Science } & \multicolumn{3}{|c|}{ Scimago/Scopus } \\
\hline Country & $\begin{array}{l}\text { Number of } \\
\text { Publications } \\
\text { in } 2010\end{array}$ & $\begin{array}{l}\text { Number of } \\
\text { Publications } \\
\text { in } 2018\end{array}$ & $\begin{array}{c}\text { Average } \\
\text { Growth } \\
\text { Rate } \\
20100 \text { - } \\
2018\end{array}$ & $\begin{array}{l}\text { Number of } \\
\text { Publications } \\
\text { in } 2010\end{array}$ & $\begin{array}{l}\text { Number of } \\
\text { Publications } \\
\text { in } 2018\end{array}$ & $\begin{array}{c}\text { Average } \\
\text { Growth } \\
\text { rate 2010- } \\
2018\end{array}$ \\
\hline Malaysia & $5963(2)$ & $15,615(1)$ & $\begin{array}{c}12.8 \% \\
(3)\end{array}$ & $15,810(2)$ & $33,295(1)$ & $9.8 \%(4)$ \\
\hline $\begin{array}{c}\text { The } \\
\text { Philippines }\end{array}$ & $801(6)$ & $2,042(6)$ & $\begin{array}{l}12.4 \% \\
(4)\end{array}$ & $1,355(6)$ & $3,775(1)$ & $13.7 \%(3)$ \\
\hline Indonesia & $1,039(5)$ & $7,464(4)$ & $\begin{array}{c}27.9 \% \\
(1)\end{array}$ & $2,884(4)$ & $32,456(2)$ & $35.3 \%(1)$ \\
\hline Singapore & $8,920(1)$ & $14,974(2)$ & $\begin{array}{c}6.7 \% \\
(6)\end{array}$ & $15,767(1)$ & $22,495(3)$ & $4.5 \%(6)$ \\
\hline Thailand & $5,257(3)$ & $10,867(3)$ & $\begin{array}{c}9.5 \% \\
(5)\end{array}$ & $10,192(3)$ & $17,943(4)$ & $7.3 \%(5)$ \\
\hline Vietnam & $1,267(4)$ & $6,040(5)$ & $\begin{array}{c}21.6 \% \\
(2)\end{array}$ & $2,196(5)$ & $8837(5)$ & $19.0 \%(2)$ \\
\hline
\end{tabular}

\subsubsection{Challenges for Research in Vietnamese higher education}

The reasons behind such modesty come from different ways the Vietnamese education is set up, with factors reflecting both the capacity and finance of university's researchers. [2]Research is weak with academics in universities having little time available due to high teaching load and access to very limited funding. Regardless of the changes noted above, most research in Vietnam is still conducted in specialized research institutes, which are not yet linked closely with teaching. Vietnamese universities are still seen more as teaching institutions that are "narrowly focused on professional training and certification to the neglect of ...other roles" [15], and to an emerging concept of "research universities" that is not well developed or understood.

The challenge also derived from an extremely low level of staff in universities with Ph.D. qualifications that fit them to undertake research effectively. Publication of research conducted in Vietnam is very low, relative to other regional neighbors, as stated in the previous section.

To conclude all of the challenges of Vietnamese university in terms of conducting research, the OECD researchers have indicated in their chapter a lack of 'a broadly shared and understood the strategic vision for university research. [11] This is reflected in ignorance among stakeholders about the research priorities of the system, the lack of support for domestic $\mathrm{PhD}$ students, and the very low degree of collaboration between public research organizations and research groups in universities.

[11]A persistent challenge for the past six years has been the development of effective relationships between university research and public research organizations, which traditionally have received most of the research funding (Nguyen, 2013[16]). Researchers count on research funding to supplement their low salaries. Principal investigators at public research organizations can face pressure from their colleagues to give opportunities to these colleagues to participate in research projects and earn extra income. This creates a barrier to extra-mural research collaboration. Faculty members at universities solve the problem of low salaries and insufficient research funding by taking on more teaching. 
This paper aims to evaluate the effectiveness of research enhancing activities carried out in a young private Vietnamese university. The university's background and research method are explained in the next section.

\section{METHODOLOGY}

\subsection{Case study: How a young Vietnamese university enhances research}

\subsubsection{University's background}

$\mathrm{X}$ University was the first private university established by an enterprise in Vietnam and led by modern educational philosophy. With more than fourteen years of history and development, X University's academic programs are adequately linked to enterprise needs and international standards, with a focus on the importance of comprehensive and harmonious human development. The immediate objective of X University is to train and provide high-quality human resources for both domestic and international businesses in professions including but not limited to Information Technology (IT), Business Administrations (BA) and Foreign Languages (FL).

In order to attain this objective, X University closely follows its vision of being 'Industry relevant, Global, Smart, and a Mega University'. Each and every component in this vision closely ties to X University's development strategies, in which research is a critical factor.

\subsubsection{Research enhancing activities of $X$ University}

As defined by the university's Board of Directors (BOD), research has become one of the four key strategies for X University's development, in addition to teaching, employability and internationalization. As stated in previous sections, research is a direct contribution to improving the quality of training. Furthermore, specifically to Vietnam, it contributes to improving Vietnamese universities' rankings on the international education map, shortening the gap between Vietnamese students and other countries' when working globally, and bringing international students to study in Vietnam.

In order to promote the research factor, the BOD of X University has implemented several activities, two of which would be the focus of this paper. They include the Research reward/Financial support system and the Researchers' quality improvement plan.

To effectively deploy the above activities, the BOD of X University also decided to establish the Office of Science Management and International Affairs (SMIA), whose main function is managing university-wide research activities. The establishment of the SMIA office in 2018 has created a department specializing in research development of X University. The office's responsibilities include consulting, proposing and amending research policies for the university; reviewing the rewarding system; and encouraging and supporting faculty members, staff and students in doing research.

Since the establishment of SMIA, research at X University has grown increasingly and outstandingly, putting $\mathrm{X}$ University on the Top 50 Vietnamese Higher educational institutions with the most international publications in 2019, according to Scopus.

$\mathrm{X}$ University's research topics cover many fields that do not limit to its three main academic majors (IT, BA and FL) but also extend on other fields such as Education and Medical, etc. Many of X University's international publications are published in Q1 and Q2 journals according to Scopus' Quartile (Q) ranking and are chosen to be presented at prestigious international conferences. All of these results bring great motivations to conducting researches at X University, as well as enhance the quality of training. 


\subsection{Data collection}

The number of X University's international publications and researchers (faculty and staff with international publications) will be analyzed in the next section in order to evaluate the effectiveness of the research enhancing activities carried out by SMIA. Data on the two variables were collected by the university's back office (2016-2017) and SMIA (2018-2020) and updated monthly on the official website of SMIA's. As mentioned in the previous section, SMIA was put in charge of developing research activities for X University. They make a yearly report on the entire system's international publications to keep track of the progress being made with the policies in place. This study extracts data from those reports. Comparison of the years 2016-2020 was made to analyze the development; the reason for the chosen time period was because we wanted to see the changes in research activities before (2016-2017), during (2018), and after (2019-2020) the policies' implementation.

\section{FINDINGS AND DISCUSSION}

\subsection{University's international publications}

First, we look at the number of overall international publications at X University throughout the analyzed time frame. Based on Figure 1, overall, the number of the X University's international publications showed the most rapid increase, especially from 2018 when SMIA was established. At the beginning of the period, it was 16 in 2016 and slightly increased to 27 in 2017. However, from 2018 to 2020, the number of X University's international publications quickly rose. In 2018, the number (66) sharply increased over two times higher than 2017 and four times higher than 2016. Moreover, the average number per year significantly went up two times compared to the previous year. In 2019, the total number of international publications of X University was 143 which dramatically grew by $116.67 \%$ compared to in 2018. It continuously sharply climbed in 2020 when it reached a peak at 257 that rose by $79.7 \%$ compared to in 2019 and rose by $289.4 \%$ compared to in 2018 .

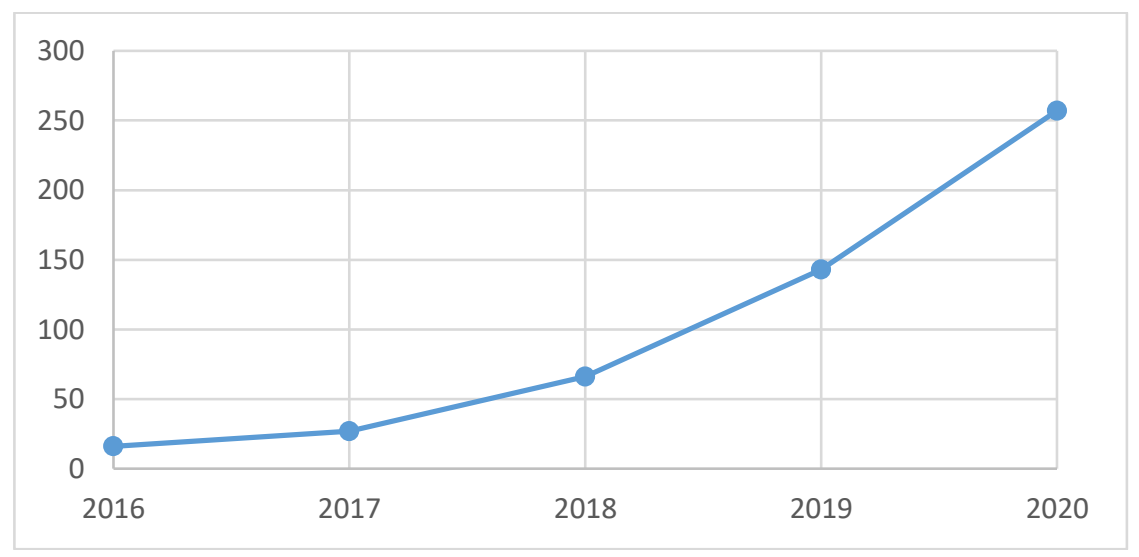

Fig. 1. The number of the $X$ University's scientific products

Regarding the topic of X University's science products, it covers the university's academic majors from IT, Mathematics (STEM) and BA, FL, Education (Social science and Humanities-SSH). Figure 2 below provides the distribution of the above two categories. 


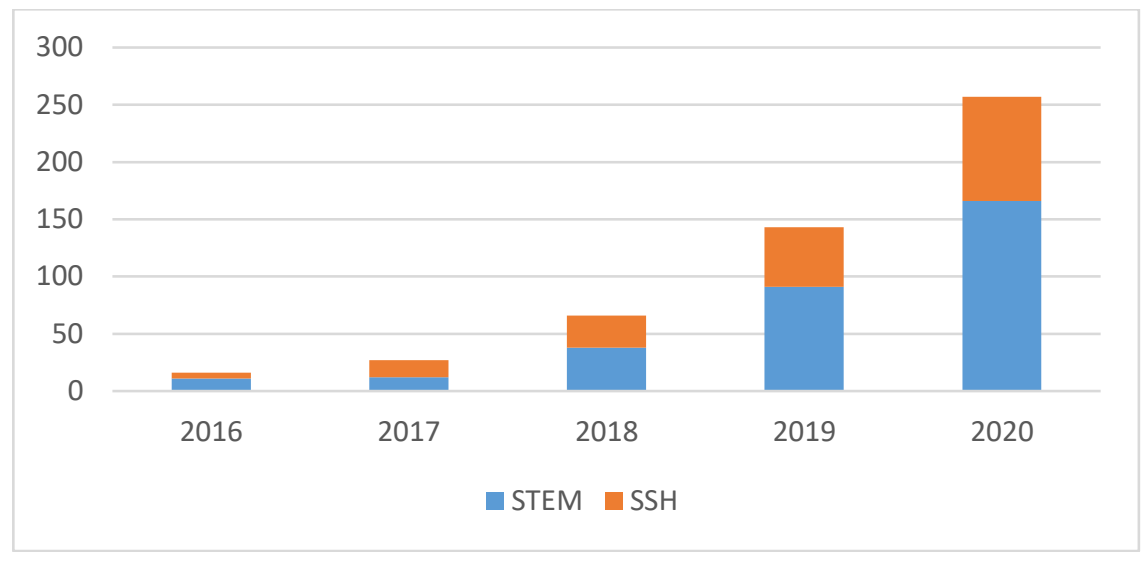

Fig. 2. The market sharing of the X University's scientific products

In 2016, there were 11 STEM publications, which was two times higher compared to SSH publications (5). In 2018, the number of STEM publications (38) was 1.4 times higher than SSH. In the 2019-2020 periods, the STEM publications were 1.8 times higher than the publications of SSH. In contrast, in 2017, there were 12 STEM publications which were lower than the SSH publications. Overall, there are more STEM publications than SSH publications. This goes in line with the worldwide trend of research, which is "ranging from natural sciences, with highly cited publications in journals containing a large number of articles, to the social sciences, with rarely cited publications in many journals containing a small number of articles", according to Jaffe K, 2014[17].

\subsection{Researchers of X university}

Next, we look at the number of faculty and staff active in conducting researches at $\mathrm{X}$ University, who we hereafter refer to as 'researchers.' Figure 3 below indicates the number of researchers in the past five years.

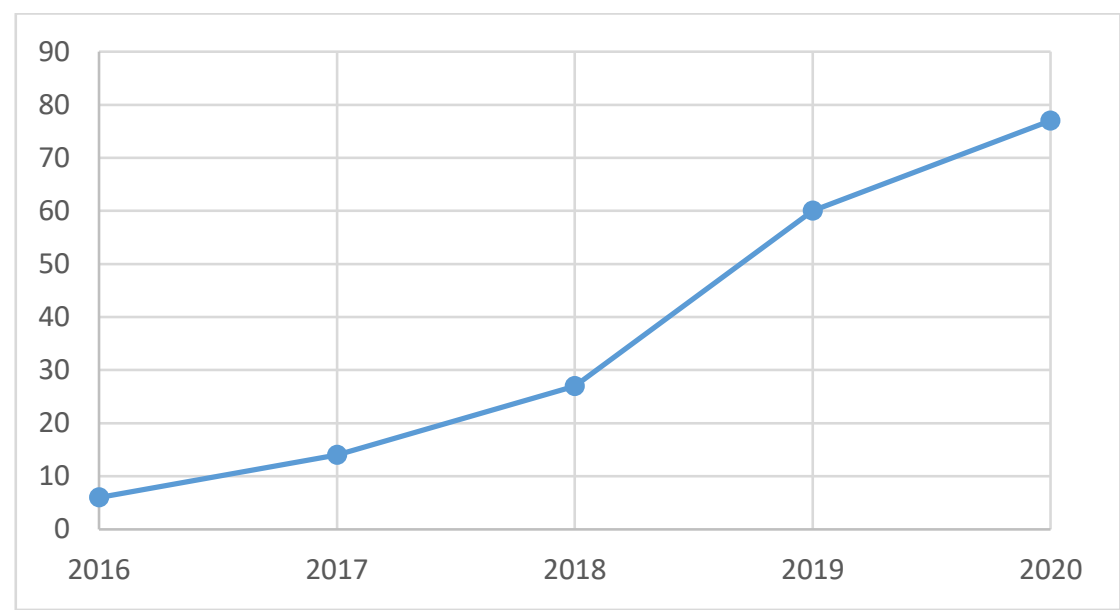

Fig. 3. The number of $X$ University faculty and staff whose scientific products 
There is a similar trend in the number of researchers as compared to international publications, which is upward. The development of X University's faculty and staff joining research has grown significantly during the period. It started at 6 in 2016 and more than doubled to 14 in 2017. In 2018, the number of researchers was 27, almost doubling from 2017 's number. In 2019, there was a very sharp jump in the number of researchers. It was at 60 , which grew by $122.2 \%$ compared to 2018 . The number kept rising until it reached 77 at the end of 2020, indicating an increase of $28 \%$ compared to the previous year and an overall growth of $185.2 \%$ since 2018 , when SMIA was established.

\subsection{Discussions}

In order to obtain the above achievements, based on SMIA's proposals, there have been frequently updated regulations on motivating faculty and staff to do research that highly support their efforts in developing the research environment at the university.

The first highlighted regulation is the creation of a rewarding system based on the Q ranking of the journals in which the research is published, making sure the researchers are rewarded appropriately for the quality of their research. On the other hand, to enhance exchanges between peers globally, there has been a different reward for those who collaborate with authors from universities in the Top 500 Quacquarelli Symonds (QS) World University rankings. With these, the rewarding policies have been giving opportunities to $\mathrm{X}$ University's faculty and staff to participate in more research projects and, at the same time, earn extra funds to maintain their research and publication, so that they do not have to rely on heavy teaching to cover expenses.

The university also supports its faculty and staff in attending international conferences to present their research, which is later published in the conference's proceedings or journals. There will be a fixed amount of grant given to pay for the attending and publishing fees.

The other highlight of SMIA's research enhancing policies deals with improving the quality of each researcher. One example is that SMIA has collaborated with the Human Resources Department of X University to promulgate a special program that aims to shift the university from teaching-based to research-based, called the 'Research scholar recruitment plan'. A research scholar ( $\mathrm{PhD}$ and higher) has fewer teaching hours compared to those of a general faculty and can spend extra time conducting research. Upon being offered a job at X University, a research scholar is required to have one international publication in ISI/Scopus journals per year. This helps increase the university's research capacity and at the same time, explains the increase in X University's quantity and quality of its international publications shown in the previous sections.

There are also other adjustments in the educational environment that help bring up the number of researchers at X University. One example was since their establishment, SMIA has organized several seminars and workshops to introduce and make research more approachable to the university's faculty and staff. These workshops have helped improved faculty and staff's understandings of research policies in and outside of the university, as well as brought in students to the field.

Another example is that SMIA has collaborated with international universities and education organizations to create an academic environment that highly supports research. They have co-organized international conferences with prestigious universities in the ASEAN region and held their own academic conferences on campus. X University's faculty, staff, and students are then given privileges such as discounted registration fees and sometimes even free listening slots. They will have the opportunities to meet, exchange, and expand their network locally and internationally, improving their own knowledge and connecting with professors and peers over the world. These are all great opportunities to form 
research projects, and most of 2020's transnational joint research has been ignited in these conferences.

Both of these highlighted policies have expanded the university's research activities in both the number of researchers and international publications from 2018 to 2020. X University's research situation has drastically changed compared to the 2016-2017 period before the establishment of SMIA, which has since taken the policies into place.

\section{CONCLUSION}

Research is playing a critical role in the sustainable development of higher education in Vietnam. At present, the performance of Vietnamese researchers in terms of international publications is somewhat modest; nevertheless, when examining the research enhancing policies of a young and dynamic Vietnamese university, we can track the growth in both numbers and quality. The research-enhancing activities at $\mathrm{X}$ University have brought solutions to Vietnamese higher education's challenges to tie research into universities' training programs, especially those private and young universities. All of the policies and programs highlighted in the previous sections help improve the research capacity (both human resources and facilities appropriate for research development). The imbalance between teaching and doing research can be eliminated with the introduction of the research scholar program, while funding problems can be solved by the rewarding system. In fact, the data above has shown outstanding results for the periods since 2018.

Nevertheless, whether X University can keep up the performance in the long run is another question to consider when evaluating the effectiveness of these research enhancing activities. Even in well-developed countries like the US or European countries, to keep a fully and sustainably developed education is challenging, not to mention in a young and fastgrowing one like Vietnam. Therefore, we have come up with a few recommendations on the current policies that are not only applicable to Vietnamese higher education but also to those of similar size and characteristics.

Firstly, regarding the research scholar recruitment plan, the requirement for a research scholar to produce one international publication per year is rather low. This number should be increased to one per term or semester in order for Vietnam to reach the milestones already met by its ASEAN neighbors. Also, the university should consider hiring scholars to only do research without having to teach to make sure the research activities are always active.

Secondly, for the long run, to balance out teaching and research at the university, as well as to shift the university from teaching-based to research-based, an establishment of a research-specific space (laboratory, classroom, etc.) should be considered. This way the research environment would be much improved. The university could build its own research-specific space or collaborate with businesses and organizations as a type of funding for its own research teams and projects.

\section{REFERENCES}

[1] Vuong, H. Q. (2019, August 28). Về Vai Trò của NGHIÊN CÚUU TRONG GIÁO dục Việt Nam Thời đại 4.0. Retrieved February 16, 2021, from http://hdll.vn/vi/nghien-cuu--trao-doi/ve-vai-tro-cua-nghien-cuu-trong-giao-duc-viet-nam-thoi-dai40.html?fbclid=IwAR2_n_wfa6bJV-nK7i1Ki76rcgDfc726PQaHdSrXtWUzUwYuxVyAWNZq_USam Anzaroot and Andrew McCallum. 2013. UMass Citation Field Extraction Dataset. Retrieved May 27, 2019 from http://www.iesl.cs.umass.edu/data/data-umasscitationfield

[2] Sheridan, G. (2010). Vietnam: Preparing the Higher Education Sector Development Project (HESDP) (Rep. No. 4207901). Asian Development Bank. Retrieved February 
$16,2021$.

[3] Tran, T., Trinh, T. P., Le, C. M., Hoang, L. K., \& Pham, H. H. (2020). Research as a Base for Sustainable Development of Universities: Using the Delphi Method to Explore Factors Affecting International Publishing among Vietnamese Academic Staf. MDPI. doi:10.3390/su12083449

[4] Tran, U. M., Dr. (2013, September 23). Https://ajc.hcma.vn/Pages/nghien-cuu-khoahoc.aspx?CateID $=679 \&$ ItemID $=3550$. Retrieved January 10, 2021, from https://ajc.hcma.vn/Pages/nghien-cuu-khoa-hoc.aspx?CateID=679\&ItemID=3550

[5] Nguyen, T. T., Tran, T., Dau, T. T., Nguyen, H. T., Nguyen, H. T., \& Ho, T. M. (2020, September 21). How scientific research changes the Vietnamese higher education landscape: Evidence from social sciences and humanities between 2008 and 2019 [Editorial]. Retrieved December 12, 2020. doi: 10.12688/f1000research.21790.1

[6] Pham L, Hayden M: Research in Vietnam: The experience of the humanities and social sciences. J Int Comp Educ. 2019; 8(1): 27-40.

[7] Salmi J, Pham TL: Academic governance and leadership in Vietnam: Trends and challenges. Journal of International and Comparative Education. 2019; 8(2): 103-118.

[8] Tran LT, Nghia TLH: Leadership in international education: leaders' professional development needs and tensions. High Educ. 2020.

[9] Lyytinen K, Baskerville R, Iivari J, et al.: Why the old world cannot publish? Overcoming challenges in publishing high-impact IS research. Eur J Inform Syst. 2007; 16(4): 317-326.

[10] Pho P, Tran T: Obstacles to scholarly publishing in the social sciences and humanities: a case study of Vietnamese scholars. Publications. 2016; 4(3): 19.

[11] OECD (2020), 'Skills and innovation: Strengthening Viet Nam's tertiary education', in Multi-dimensional Review of Viet Nam: Towards an Integrated, Transparent and Sustainable Economy, OECD Publishing, Paris. Doi: https://doi.org/10.1787/482cd95fen

[12] Pham, T. (2012), "The Renovation of Higher Education Governance in Vietnam and its Impact on the Teaching Quality at Universities", Tertiary Education and Management, Vol. 18/4, pp. 289-308, http://dx.doi.org/10.1080/13583883.2012.675350.

[13] Scopus. Scimagojr. Available online: https://www.scimagojr.com/

[14] Pham, D.-H. A comparative study of research capabilities of East Asian countries and implications for Vietnam. High. Educ. 2010, 60, 615-625.

[15]P.T Nghi, "The Higher Education Reform Agenda: A vision for 2020" in Harman, Hayden, and Nghi (Eds) Reforming Vietnam's Higher Education, Springer, 2010, p 56

[16] Nguyen, T. (2013), "The challenges of developing research resources for leading Vietnamese universities", Higher Education Management and Policy, Vol. 24/2, https://dx.doi.org/10.1787/hemp-24-5k3w5pdwd7g4.

[17] Jaffe K. Social and natural sciences differ in their strategies, adapted to work for knowledge landscapes. PLoS ONE.(2014) 9:e113901.doi: https://doi.org/10.1371/journal.pone.0113901 